
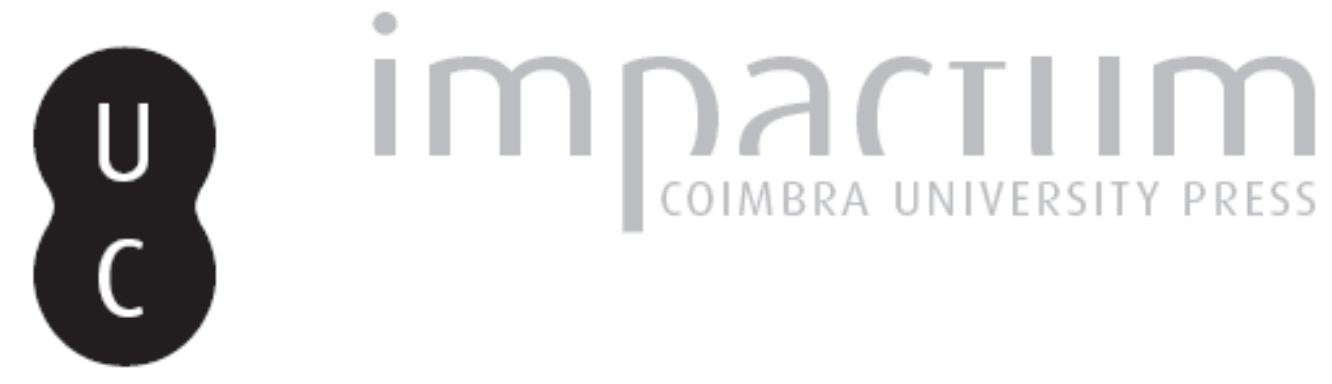

Certezas, incertezas e contradições: um percurso na escrita de Carlo Goldoni

Autor(es): $\quad$ Peixoto, José

Publicado por: Imprensa da Universidade de Coimbra

URL persistente:

URI:http://hdl.handle.net/10316.2/42637

DOI:

DOl:https://doi.org/10.14195/0870-8584_2_3

Accessed : $\quad$ 26-Apr-2023 15:58:14

A navegação consulta e descarregamento dos títulos inseridos nas Bibliotecas Digitais UC Digitalis, UC Pombalina e UC Impactum, pressupõem a aceitação plena e sem reservas dos Termos e Condições de Uso destas Bibliotecas Digitais, disponíveis em https://digitalis.uc.pt/pt-pt/termos.

Conforme exposto nos referidos Termos e Condições de Uso, o descarregamento de títulos de acesso restrito requer uma licença válida de autorização devendo o utilizador aceder ao(s) documento(s) a partir de um endereço de IP da instituição detentora da supramencionada licença.

Ao utilizador é apenas permitido o descarregamento para uso pessoal, pelo que o emprego do(s) título(s) descarregado(s) para outro fim, designadamente comercial, carece de autorização do respetivo autor ou editor da obra.

Na medida em que todas as obras da UC Digitalis se encontram protegidas pelo Código do Direito de Autor e Direitos Conexos e demais legislação aplicável, toda a cópia, parcial ou total, deste documento, nos casos em que é legalmente admitida, deverá conter ou fazer-se acompanhar por este aviso.

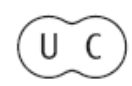




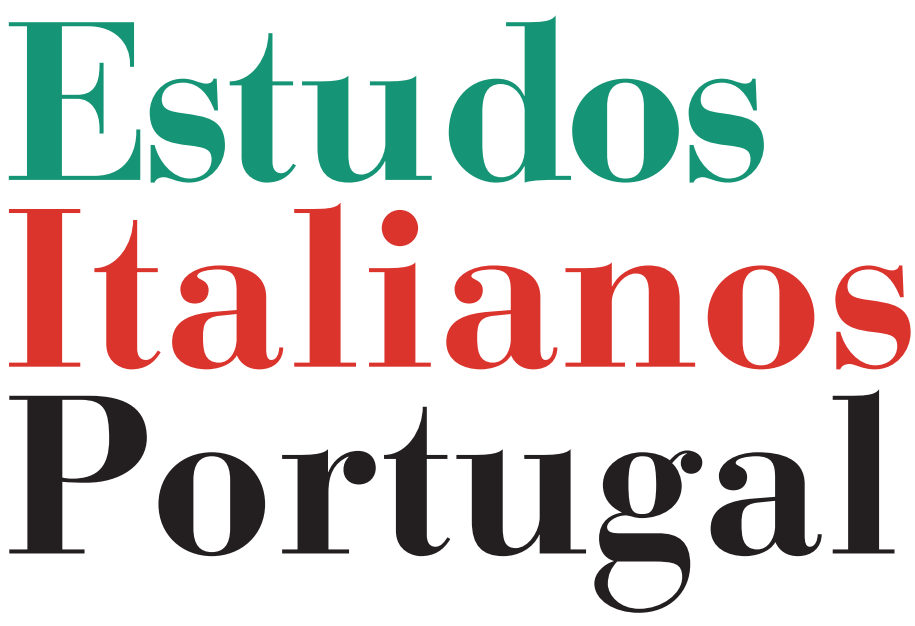

Instituto

Italiano

de Cultura

de Lisboa

Nova Série

$\mathbf{N}^{\mathbf{0}} 2$ 


\title{
CERTEZAS, INCERTEZAS E CONTRADIÇÕES. UM PERCURSO NA ESCRITA DE CARLO GOLDONI
}

\author{
José Peixoto*
}

Recebi um sms que dizia "Querido pai. Estou na casa do teu Mestre. Ele manda abraços. Devias estar aqui comigo. Beijos. Miguel". Senti uma grande satisfação.

Não era a primeira vez que alguém, espectadores, amigos ou alunos, ia a Veneza, à Casa Goldoni ou ao Teatro Goldoni e me dava depois conta disso.

Ter levado alguém a conhecer Goldoni, ter partilhado com alguém o prazer do teatro de Goldoni, tornando, em Veneza, Goldoni visita obrigatória, dá-me a sensação de ter acrescentado alguma coisa interessante ao nosso pequeno mundo e isso dá-me um grande bem-estar.

Mas ao Mestre peço que me desculpe por não ser mais diligente, por não o ter estudado mais, por não ter divulgado mais as suas comédias, por não ter demonstrado de forma eficaz a actualidade do seu teatro, ao público, aos programadores dos teatros e aos políticos que distribuem os dinheiros que tornam possíveis os empreendimentos teatrais.

\footnotetext{
* José Peixoto - Actor e encenador. Licenciou-se em História. Profissional com Os Bonecreiros. Estágios com Bernard Sobel no Théâtre de Gennevilliers e com Giorgio Strehler no Piccolo Teatro di Milano. Esteve na equipa inicial do Centro Cultural de Évora. Co-fundador do Teatro da Rainha. Director do Teatro Malaposta de 87 a 99. Foi professor na Escola Superior de Teatro e Cinema, Presidente do Conselho Científico e Director do Departamento de Teatro. Pertence à Direcção do Teatro dos Aloés, companhia de actores fundada em 2000.
} 
Com ele já aprendi muita coisa, do Mundo e do Teatro, e só li pouco mais que $1 / 4$ dos textos que escreveu.

Primeiro li-o em colectâneas de "Capolavori" organizadas com o saber de estudiosos de renome que me davam a garantia de ter lido as obras mais significativas do Mestre.

As escolhas nunca coincidiam e eu devia ter desconfiado que devia haver mais "obras-primas" do que aquelas que me recomendavam. E na verdade continuo a descobri-las com regozijo.

As "obras-primas" dependem das projecções que cada época faz de si própria sobre a obra dos autores. Umas vezes são nossos contemporâneos, outras vezes esquecemo-los por muito tempo. As escolhas são pessoais e subjectivas, têm sempre data e assinatura.

E talvez seja isso um Clássico, um manancial inesgotável de experiências, de reflexão e conhecimento humano, que se projecta para além da História, que regressa sempre como um cometa e nos acompanha através dos tempos e onde cada um vai buscar o que lhe é útil para definir o seu próprio caminho no Mundo e no Teatro.

Em Goldoni, como certeza e antes de tudo, diria que me fascina o Teatro como instrumento de análise, revelação e compreensão do Mundo, como experiência da Vida.

Talvez seja isto mesmo o que me ocupa e mantém no teatro com entusiasmo.

E estas razões são as de Goldoni, creio eu.

Vejo o Mestre empenhado numa luta por uma reforma que nos dê um teatro com responsabilidade cívica e moral, com propósitos de contribuir para uma transformação das mentalidades e da sociedade. Ouço-o a discutir e a reflectir com outros que também e antes dele tentavam reformas "concluindo que o teatro ia de mal a pior e tinha necessidade de ser reformado" e que " era preciso levar progressivamente o espectador a provar o melhor para se apaixonar pelo bom”. 
E terá começado assim com arlequins e pantalones que já não eram só um divertimento e exerciam, na sociedade e no teatro, funções bem diferentes, embora tivessem os mesmos nomes.

Vejo-o ocupado a escrever para um teatro que pretende ter um público universal e menos rigoroso na estruturação do seu espaço dividido por classes. Vejo-o ocupado com o maior número, rejeitando elites do saber ou do dinheiro, deixando de lado as pequenas tragédias privadas, mas sabendo que a vida é feita de pequenas coisas e não de grandes gestos.

Até o vejo a calar o orgulho, pedindo protecção e privilégios ou humilde a dedicar comédias a quem podia fazer funcionar o seu teatro, pensando em silêncio para si próprio, que o melhor era mesmo não depender de ninguém.

Imagino-o a olhar a realidade com a segurança científica que as Luzes lhe permitiam e tomar posição na definição do rumo que a sociedade, no seu entender, devia seguir.

Aprecio nele a capacidade, e a coragem, de mostrar na cena as virtudes e os vícios das classes em confronto.

Filho da burguesia não se cansa de enaltecer as capacidades dessa classe que abria novos caminhos para o desenvolvimento da humanidade, servindo-se da cena para zurzir impiedosamente uma aristocracia que se lhe afigurava improdutiva e inútil.

Mas a forma de apreensão do real permitiu, a ele e a nós também, a revelação das contradições dessa classe em ascensão, o ciclo da sua evolução e as razões da sua decadência.

Acredito que ele acreditava no teatro como um meio de compreender as pessoas e as sociedades, a ele próprio e a sua relação com os outros. E que tinha a convicção de que, "não podemos deixar este mundo como o encontrámos, é preciso acrescentar qualquer coisa".

Depois de castigar a fidalguia e de se ter rido das contradições dos comportamentos da sua própria classe, sentiu necessidade de alargar o objecto da sua observação. 
Chegaram a cena os habitantes de O Campiello que passou a ser mais um mundo em análise, e as Cozinheiras passaram a ser pessoas com história própria e não complemento dos seus amos, e as mulheres dos pescadores de Chioggia vieram fazer renda de bilros para a boca de cena, enchendo o palco com a sua Algazarra, as suas conversas e as suas disputas, enquanto esperavam os maridos que traziam para os teatros o cheiro a mar e a peixe.

Alguns não gostaram e resolveram não voltar ao Teatro de Goldoni, preferindo outros espaços onde outros autores levavam à cena fantasias boas para uma boa digestão, sem implicar problemas sociais ou gente mal cheirosa ou ter que ouvir falar de política.

Alguns burgueses Rústicos ainda pensavam ser uma virtude não ir ao teatro e a gente do "Campiello" ou os pescadores de Chioggia não deviam ter dinheiro para pagar o bilhete.

Goldoni tinha inimigos impiedosos que viam o mundo deles e os seus privilégios postos em causa, compreendendo que a reforma não era só estética e que o teatro se transformara num poderoso espelho da realidade e instrumento de uma tomada de consciência cívica. Não podiam perdoar ao Poeta e desencadeavam por isso ataques ferozes.

Então o Mestre sentiu que seria mais útil ir fazer a sua reforma longe dessa guerra de rivalidades artísticas e ideológicas e trabalhar perto de quem o compreendesse e aceitasse, e partiu para Paris, cidade das Luzes, onde as ideias e as pessoas estavam em movimento.

Tinha escrito já o melhor da sua obra, diz a crítica.

Não nos deixava os grandes gestos dos grandes heróis, mas a sinfonia do quotidiano, onde a sucessão das pequenas coisas e dos pequenos acontecimentos nos revelava um mundo complexo de gente complexa e contraditória, uma realidade não feita de ideias sobre a vida, mas o desdobrar da própria vida organizada em demonstração. Alguma coisa para pensar e para quem faz do pensar um prazer. 
$\mathrm{E}$ as personagens na cena iam assumindo protagonismo $\mathrm{e}$ deixando depois o lugar vago para que a personagem seguinte tivesse ocasião de dizer o que tinha para dizer, não usurpando lugares, mas pondo em confronto as opiniões.

No lugar de um herói um coro de pessoas que nos dizem como as pessoas são parecidas e como são diferentes. Não a ideia simples do desenvolvimento do comportamento de uma personalidade, mas a multiplicidade dos comportamentos que se cruzam na realidade da vida.

$\mathrm{E}$ as personagens não se definiam num quadro de ideias preestabelecidas, iam definindo-se no relacionamento contraditório com os outros e enquanto agiam e tomavam atitudes. Como na vida.

E as histórias na sua aparente simplicidade tornavam-se complexas porque há sempre mais alguma coisa que precisamos compreender do comportamento humano, ou que a história se pode contar de outra maneira, que a verdade não é só uma, que há outras razões que explicam os comportamentos, que há sempre alguma coisa que está por detrás da outra e que não se revela logo, nem talvez se revele nesse mesmo texto, ou que só compreendemos quando estamos a trabalhar uma outra comédia, como se cada texto nos fizesse compreender o que não compreendemos no texto anterior, como se nos tornássemos mais maduros e mais sábios através da leitura atenta da sua obra.

E por isso os encenadores que abordam Goldoni uma vez sentem necessidade de o abordar uma e mais outra vez, como um fenómeno de escalada de compreensão, ou a consciência adquirida no fim de cada encenação que o trabalho afinal não está completo e a obra não está acabada.

Mas Goldoni não tem sido feito entre nós, como antes já foi, como a sua arte, a sua inteligência e a sua actualidade mereciam.

Porquê?

Porque a superficialidade faz de Goldoni um autor do passado, porque o confundimos com aquilo que ele com- 
bateu, porque dele traduzimos quase nada, porque as traduções não são editadas e acabam por servir muito poucos, não formando nem actores nem público, porque de facto não o conhecemos.

E no entanto já vimos as demonstrações de entusiasmo do público e dos actores, velhos e novos, perante as comédias de Goldoni.

Mas sobretudo porque não temos meios.

Se as personagens são todas protagonistas à vez, as companhias que querem fazer Goldoni não podem organizar-se à volta de um talento a que outros vão dando réplicas. Com Goldoni os actores precisam ser todos talentosos e sem esta condição os espectáculos não poderão passar ao público toda a riqueza dos textos.

Goldoni escreveu de facto para actores, por isso a sua reforma tenta renovar em simultâneo a escrita e o actor.

A verdade, a simplicidade, o natural, o interesse dramático e a arte estavam ou deviam estar no actor criador da materialidade da cena.

Assim a reforma foi sendo feita com os actores, com os seus conselhos e a sua experiência, dignificando a profissão, dando-lhe um sentido ético e responsabilidade social.

Sempre me disseram que o teatro é "Aqui e Agora".

Quando criamos um espectáculo, criamo-lo para alguém que está vivo diante de nós e com quem podemos falar sobre coisas de hoje e por causa de coisas de hoje, mesmo quando utilizamos uma linguagem que não é a nossa ou que não é a do nosso tempo, alguém que procuramos motivar com as nossas ideias, a nossa visão do mundo, as nossas razões ou os nossos afectos.

A comunicação entre a cena e a sala só se efectiva se quem estiver na sala dominar os códigos dos sinais que a cena produz. A cena e a sala fazem um só mundo com duas faces.

E, como em qualquer comunicação, a mensagem só passa se houver uma informação prévia que pertença à cena e à sala. 
Todos os textos têm uma data, mesmo os do nosso tempo. Alguns são tão geniais que ultrapassam o seu tempo e continuam a trazer-nos ensinamentos úteis, enriquecedores e belos.

Mas os textos para serem compreendidos pela sala precisam de ser explicitados pela cena, que tem de os compreender primeiro. Têm os textos assim de ser informados e situados numa realidade sociocultural, num tempo.

No meu trabalho de encenador ou actor, precisei sempre de saber essa data, conhecer o tempo e as condições em que a obra nasceu.

Precisei de perceber o que estava por detrás das palavras, saber para que gente tinha sido aquele texto escrito e com que intenção, em que quadro social, histórico e mental se inseria. Precisei de uma ideia chave de leitura que me guiasse, sabendo que as palavras mudam de significado quando mudamos o quadro da sua existência.

Quando conseguia uma intimidade com o texto, caminhando nele em várias direcções, quando o relacionava com o seu quadro histórico, ou era capaz de definir o mundo material e espiritual que lhe dera origem, conseguia ter ideias para propor à cena e o resultado do trabalho passava para o público e isso traduzia-se em gente na sala e sobretudo em gente que falava sobre o que vira, que tinha opiniões e que gostava de as expressar.

Quando datava um texto compreendia-o e dava mais um contributo para o tornar universal, intemporal ou para o libertar do tempo.

Quando não atingia esse grau de conhecimento, quando não tinha as razões das coisas ou a ideia-chave, quando não estabelecia o relacionamento dos acontecimentos e das falas com as razões das personagens, as imagens eram difusas, desfocadas, os sinais pouco expressivos e o público ficava com a sensação de não ter percebido nada. A mensagem não passava.

Para expor um quadro de uma existência humana é preciso percebê-lo. 
Um texto de teatro não é um amontoado de palavras que possamos reorganizar ao nosso belo prazer, cortando ou não incluindo no espectáculo o que não percebemos e achando que tudo fica melhor se o adaptarmos à imagem do nosso tempo, que geralmente é a imagem da nossa ignorância sobre os tempos da origem dos textos.

Clara é a diferença de atitude quando Brecht reescreve Shakespeare ou Heiner Müller reescreve Sófocles. Aí estamos perante tentativas de perceber e fazer perceber mecanismos de poder ou comportamentos psicológicos cujas condições de existência mudaram com o tempo.

Os que escreveram ou fizeram teatro antes de nós, fizeram-no para as mulheres e os homens do seu tempo e só compreendendo como dialogaram no seu tempo e sobre que inquietações reflectiram podemos transformar o seu legado em coisa útil para nós.

Mas se devemos estabelecer essas coordenadas não podemos também ignorar a relação da cena e da sala no nosso tempo.

Um Clássico é uma árvore frondosa que produz muitos frutos, mas as árvores frondosas têm com muita frequência ramos secos que é preciso cortar para rejuvenescimento da árvore e garantia de continuação da vida.

Podar é uma arte e uma ciência. Quem não as domina não deve fazer cortes nem enxertos porque corre o risco de matar a árvore.

Mas perante um legado de tanta sabedoria que tanto nos enriquece, mostrar como as obras ficam prisioneiras do seu tempo é uma atitude sem utilidade cultural ou social.

Os clássicos amedrontam talvez e um respeito reverente inibe certamente, mas não podemos deixar de ter o propósito claro de os aproximar do nosso público, de optar pelas formas que o relacionem com o nosso tempo, fazendo deles coisas vivas e não objectos do passado.

Tento que os espectáculos produzam no espectador o prazer de pensar sobre o que se passa em cena. Que seja 
possível a cada um dizer - "os problemas daqueles homens dizem-me respeito, eles não sabem como resolvê-los, mas eu sei." Ou se não tivermos ainda uma resposta que fique a necessidade de a saber.

Os códigos que utilizo são os de agora e tento conservar a essência da obra e da época, e apago o acessório, o circunstancial, o decorativo.

Agrada-me observar os episódios bíblicos pintados pelos artistas do Renascimento que não pretendiam reconstituir o "tempo da Bíblia", mas em alerta porque o tempo promove o desaparecimento do quotidiano e os textos tornamse abstractos, paradigmas que tendem para parábolas.

Procuro conservar os comportamentos, as atitudes e os confrontos de interesses com as razões e as explicações do seu tempo e provocar a atitude de perplexidade do espectador perante esses factos, escolhendo soluções cénicas para cada caso, sem ignorar que trabalho para espectadores de hoje e que recusamos as mensagens que não deciframos.

Procuro relacionar-me com a matéria com que trabalho sem preconceitos, fazendo de cada espectáculo uma experiência nova, no sentido de tentar perceber alguma coisa mais dos comportamentos humanos, sem saber quando começo aonde vou chegar.

Cada texto tem a sua autonomia que não permite nem receitas, nem conclusões antes do início do trabalho. Nenhuma dramaturgia pode prever o que acontece quando os actores representam na cena. E se já soubéssemos tudo o que o texto quer dizer não valeria a pena fazer o espectáculo, nem entrar nessa experiência galvanizante e transformadora que é o teatro.

Carlo Goldoni terá as determinações do seu tempo, mas o seu Teatro, a sua reflexão sobre o Mundo é matéria que continuamos a tentar decifrar com prazer e beneficio.

Se pensar tivesse no nosso tempo alguma importância seria mesmo fascinante discutir com Carlo Goldoni, pondo em 
causa as suas conclusões, as suas utopias sobre o Mundo e o Teatro, propondo outras formas, correndo riscos, experimentando, falhando, recomeçando, buscando novas formas, não tendo nada definitivo, nem acabado, fazendo do Teatro um instrumento que é preciso reformar para ser útil à transformação do Mundo, fazendo hoje o equivalente ao que ele assumiu fazer no seu tempo. Creio que isso daria prazer ao Mestre. 